\title{
Small Bone Defects Augmentation
}

\author{
Cristian RAŢIU ${ }^{1}$, Simona CAVALU ${ }^{1}$, Adina Bianca BOŞCA² Flavia RUXANDA ${ }^{3}$, Vasile RUS ${ }^{3 *}$, \\ Viorel MICLĂUŞ3
}

${ }^{1}$ University of Oradea, Faculty of Medicine and Pharmacy, Oradea; " "Iuliu Haţieganu” University of Medicine and Pharmacy, Cluj-Napoca; ${ }^{3}$ University of Agricultural Sciences and Veterinarian Medicine, Cluj-Napoca, Romania.

*Corresponding author e-mail: vasilerus2002@yahoo.com

Bulletin UASVM Veterinary Medicine 71(2) / 2014,

Print ISSN 1843-5270; Electronic ISSN 1843-5378

DOI:10.15835/buasvmcn-vm: 10537

\begin{abstract}
The aim of the study was to compare different techniques for small alveolar crest bone defect augmentation with implants adapted to these bone defects. Platform switching; machined collar and zirconia collar implants were placed in the upper and lower jaw in two patients. The bone was placed around the implant on the buccal side and stabilized with osteosynthesis screws. Zirconia collar implant is a very simple method to apply, which can be also useful in the esthetic zone for soft tissue support; its white colour also plays an important esthetic role.
\end{abstract}

Key words: bone defect, implant, zirconia collar.

Introduction. Tissue integration of endoosseous implants, esthetic outcome and long term maintaining of these benefits are now the requirements of modern implantology. An important criterion for this procedure is implant insertion inside the bone contours (Khoury et al., 2007). The bone can be collected from the burr using drilling without cooling (Anitua et al., 2003) or from the area of implant socket with a trephine drill (Khoury et al., 2007). In cases when the implant cannot be inserted completely inside the contours, stabilizinf the graft is necessary. A safer alternative is implant insertion after healing of the grafted bone. A dental implant with a sloped marginal contour, Osseo Speed Profile (Astra Tech AB, Molndal, Sweden) has been developed to optimize implant placement in such situations. Thanks to its biocompatiblity, Y-TZP zirconia of the TBR ${ }^{\circledR}$ hybrid zirconia-titanium implant is well tolerated by soft tissues, improving long-term peri-implant soft tissue stability (Marzouk, 1996). Also zirconia ceramic implants are osseointegrable (Cavalu et al., 2014). Use of different techniques for small alveolar crest bone defect augmentation in comparison with implants adapted to these bone defects.
Materials and methods. Prior to surgery, blood was harvested from the cephalic vein of the forearm, in ten $5 \mathrm{ml}$ vacutainers containing $3.8 \%$ sodium citrate. The blood was centrifugated for 8 minutes at a $460 \mathrm{G}$ speed, based on the technique described by Anitua et al. (2001). After centrifugation, plasma is separated with the pipette into three fractions. The volume of fraction 1 is variable, depending on the hematocrit, and the volume of fractions 2 and 3 is constant, being $0.5 \mathrm{ml}$. Fraction 1 (PPGF) represents plasma poor in growth factors, contains a small number of platelets and is used to obtain the fibrin membrane. Fraction 2 (PGF) contains growth factors in equal quantity to those present in the peripheral blood. Fraction 3 (PRGF) is plasma rich in growth factors, their concentration here is 2.5-3 times higher than in the peripheral blood. All three fractions require activation with $10 \%$ $\mathrm{CaCl}_{2}$ before use. To achieve maximum effect, fractions 1 and 2 must be activated 30-40 minutes before use, and fraction 3, 8 minutes before use. Platform switching implants (M implant - TBR®), machined collar implant (Conic implant - TBR $囚$ ) and hybrid zirconia-titanium implants (Z1 conic system - TBR®) were placed in upper and lower 

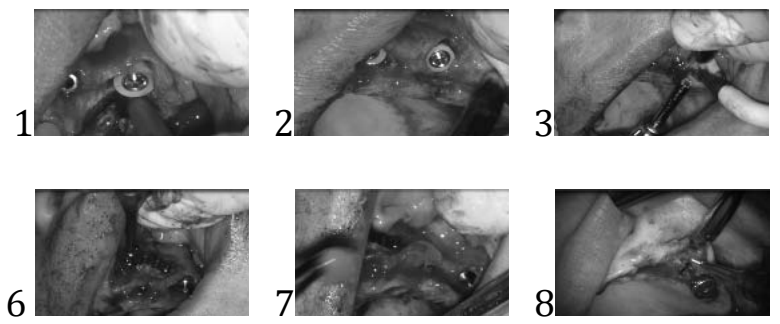
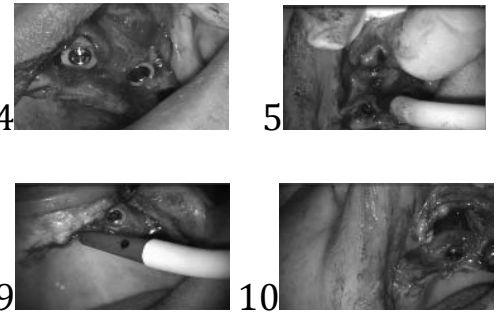

Fig. 1. Zirconia collar implant placed after extraction of 2.3 subcrestal mesial, distal, buccaly and supracrestal on palatal plate due to bone loss.

Fig. 2. Zirconia collar implant placed after extraction of 2.5 subcrestal mesial, distal, palatal; bone loss on bucal plate can be noticed.

Fig. 3. "Bone carrot" harvesting with a trephine burr.

Fig. 4. Bone grafting fixation on buccal plate with osteosynthesis screw.

Fig. 5. Bone loss on buccal plate.

Fig. 6. Bone (recovered from drills during implant site preparation without cooling) grafting with titanium mesh fixed with osteosynthesis screws.

Fig. 7. Covering of the entire area with fibrin membrane.

Fig. 8. Second step surgery: healing screws mounting; "bone carrot" graft integration can be noticed.

Fig. 9. Zirconia collar implant osseointegration; zirconia osseo and gingiva integration can be observed.

Fig. 10. Bone graft integration can be noticed after titanium mesh removal.

jaw in two patients. The hybrid zirconia-titanium implant was placed with the zirconia collar, buccally subcrestal and palatally supracrestal (Fig. $1,2)$. A trephine burr with a inner diameter of 2,5 mm was used to extract a "bone carrot" at the site of implant placement; the bone was placed around the implant on the buccal side and stabilized with a osteosynthesis screw (Fig. 3-6) (Stoma®). Drilling for implant placement was performed without cooling (Anitua et al., 2003) and the autologous bone was recovered from drill's treads. The bone, mixed with fraction 3 , was placed on the buccal wall perforated by the implant treads, then stabilized with a titanium mesh and osteosynthesis screws (Trinon $®$ ). Fibrin membrane was used to cover the entire wound before closure (Fig. 7, 8).

Results and discussions. In the first case, an apical reposition flap was performed in order to increase attached gingiva width after 4 months; the healing screws were placed into the implants, concomitantly. X-ray examination showed implant osseointegration and also bone graft integration. After bone exposure, osteosynthesis screws were removed, and the bone graft vascularization and integration into the surrounding bone was noticed. Zirconia collar osseointegration was also noticed (Fig. 9). In the second case, the flap was raised and bone growth on the implant surface was noticed; the bone graft vascularization was noticed also in the second case (Fig. 10).

Conclusion. If the bone graft is well stabilized with osteosynthesis screws, vascularization and graft integration in the surrounding bone is achieved; in the case of esthetic zone this may be very important. On the other hand, zirconia collar implant is a very simple method that can be also useful in the esthetic zone for soft tissue support; its white colour also plays an important esthetic role.

\section{References}

1. Anitua E., I. Andia, C. Carda, (2003). BTI: New process for drilling, placing implantsand obtaining autologous bone. Dental Dialogue, Vol. 1, 3- 10.

2. Anitua E.A., I.O. Andia, P. Nurden, (2001). A New Aproach to Bone Regeneration Plasma Rich In Growth Factors. Puesta Al Dia Publicaciones, 81-145.

3. Cavalu S., C. Ratiu, O.Ponta, V. Simon, D. Rugina, V. Miclaus, I. Akin, G. Goller, (2014). Improving osseointegrationof alumina/zirconia ceramic implants by fluoride surface treatment. Dig. J. of Nanomat. and Biostr.. 9 (2): 797-808,

4. Khoury F., H. Antoun, P. Missika, (2007). Bone Augmentation in Oral Implantology. Quintessence, 16 -387.

5. Marzouk J., (1996). Two applications of transmucosal milled ceramic in implantology : Preliminary clinical examples. Quintessence International, Volume 27. 